\title{
Disruption of reproductive development in male rat offspring following gestational and lactational exposure to di-(2-ethylhexyl) phthalate and genistein
}

\author{
Lian-Dong Zhang ${ }^{1}$, Qian Deng ${ }^{1 \#}$, Zi-Ming Wang ${ }^{1}$, Ming Gao ${ }^{2}$, Lei Wang ${ }^{1}$, Tie Chong ${ }^{1}$ and He-Cheng Li ${ }^{1}{ }^{*}$ \\ 1 Department of Urology, the Second Affiliated Hospital, School of Medicine, Xi'an Jiaotong University, Xi'an 710004, Shaanxi, People's Republic of China. \\ 2 Department of Nephrology, Xi'an No.4 Hospital, Xi'an 710004, Shaanxi, People's Republic of China.
}

\begin{abstract}
Studies of developmental effects of mixtures of endocrine disrupters on the male reproductive system are of great concern. In this study, the reproductive effects of the co-administration of di-2-(ethylhexyl) phthalate (DEHP) and genistein (GEN) during pregnancy and lactation were studied in male rat offspring. Pregnant Sprague-Dawley rats were gavaged from gestation day 3 to postnatal day 21 with vehicle control, DEHP $250 \mathrm{mg} / \mathrm{kg}$ body weight (bw)/day, GEN $50 \mathrm{mg} \mathrm{kg}$ bw/day, GEN $400 \mathrm{mg} \mathrm{kg}$ bw/day, and two combinations of the two compounds (DEHP $250 \mathrm{mg} / \mathrm{kg}$ bw/day + GEN $50 \mathrm{mgkg}$ bw/day, DEHP $250 \mathrm{mgkg}$ bw/day + GEN $400 \mathrm{mgkg}$ bw/day). The outcomes studied were general morphometry (weight, AGD), testicular histology, testosterone levels, and expression at the mRNA level of genes involved in steroidogenesis. Organ coefficient, AGD / body weight ${ }^{1 / 3}$, serum testosterone concentration and genes involved in steroidogenic pathway expression when exposed to DEHP (250mg/ $\mathrm{kg}$ bw/day), GEN $(50 \mathrm{mg} / \mathrm{kg}$ bw/day) or GEN( $400 \mathrm{mg} / \mathrm{kg}$ bw/day) alone were not significantly different from the control group. When exposed to (DEHP $250 \mathrm{mg} / \mathrm{kg}$ bw/day $+\mathrm{GEN} 50 \mathrm{mg} / \mathrm{kg}$ bw/day) together during pregnancy and lactation, serum testosterone concentration, epididymis coefficient and Cypal17a1,Scarb1 m RNA expression significantly decreased compared to the control and GEN(50mg/ kg bw/day). When exposed to (DEHP 250mg/kg bw/day +GEN 400mg/kg bw/day) together during pregnancy and lactation, AGD / body weight ${ }^{1 / 3}$, serum testosterone concentration, testis and epididymis coefficient and Star, Cypal17a1 mRNA expression appeared significantly decreased compared to the control and DEHP/GEN single exposure, together with developmental impairment of seminiferous tubules and seminiferous epithelium. Overall, co-administration of DEHP and GEN during gestation and lactation seem to acts in a cumulative manner to induce the most significant alterations in the neonate, especially with GEN at high dose, although the effect of the DEHP-GEN mixture on adult offspring should be observed further.
\end{abstract}

Key words: Di-2-(ethylhexyl) phthalate, genistein, pregnancy, lactation, reproductive system.

\section{INTRODUCTION}

It is well recognized that humans and wild animals are exposed to multiple endocrine-disrupting chemicals (EDCs) simultaneously (Main et al., 2010; TM et al., 2006; Toppari et al., 2010). Di-2-(ethylhexyl) phthalate (DEHP), the most widely used plasticizer in polyvinylchloride plastics, is used in cosmetics, pharmaceuticals, lubricant oils and solvents, comprising about $80 \%$ of the phthalate consumption in the world (Kamrin, 2009). Since phthalate plasticizers are not chemically bound to PVC, they can leach, migrate or evaporate into indoor air and atmosphere, foodstuffs, other materials, etc. Especially since the "Plasticizer Crisis" occurred in May 2011 in Taiwan, DEHP arouses concern about its antiandrogen effects (Fisher, 2004). Genistein, a soy-derived product, is widely present in the diet of the eastern world (Duncan et al., 2003). Phytoestrogen consumption during pregnancy and in infants through soy-based formulas is of great concern (Cederroth et al., 2010; Strom et al., 2001).

DEHP exerts anti-androgen effect by suppressing fetal testosterone biosynthesis via peroxisome proliferatoractivated receptor (PPARs) activation (Culty et al., 2008), resulting in a series of reproductive tract defects in male offspring (Christiansen et al., 2010; Foster, 2006; Lagos-Cabre
\& Moreno, 2012; Pocar et al., 2012) .The spectrum of effects is characterized by disrupted androgen-dependent development and increased incidence of hypospadias, cryptorchidism, impaired spermatogenesis and testicular cancer, which collectively comprise the testicular dysgenesis syndrome (TDS) (Hu et al., 2009). In both humans and rodents, fetal Leydig and Sertoli cell dysfunction seems to play a vital role in the development of TDS or TDS-like symptoms. In the rat model, DEHP exerts an anti-androgen effect mainly by suppressing fetal testosterone biosynthesis (Culty et al., 2008).

Genistein can mimic the actions of estrogen and behave as an antioxidant. Exposure to genistein, especially during pregnancy and lactation, can cause disruption of the reproductive system development in a dose-dependent way (Lehraiki et al., 2011; Wisniewski et al., 2003; Wisniewski et al., 2005). It is also interesting to note that genistein could enhance fertility by promoting acrosome reaction at lower doses, but potentially suppress male fertility via suppressing acrosome reaction at higher doses, having no significant effect on sperm morphology (Kumi-Diaka et al., 1999). It has also been shown that isoflavones can reduce the negative effects of cypermethrin on reproductive characteristics of mature male rabbits (Yousef et al., 2003).

Although many studies have examined the effects of single EDC using in vitro or in vivo assays (Christiansen et al., *:Corresponding author: He-Cheng Li, M.D. Department of Urology, the Second Affiliated Hospital, School of Medicine, Xi'an Jiaotong University, No.157 Xiwu Road, Xi'an 710004, Shaanxi
Province, P R. China. Tel:+86-29-8767-9442 Fax: +86-29-8767-9311 ;E-mail: lihecheng@yahoo.com.cn

Received: November 5, 2012. In Revised form: February 25, 2013 Accepted: March 28, 2013

\#: This author contributed equally to this study and shares first authorship 
2010; Roberts et al., 2000), few studies have been conducted to examine the effects of mixtures of EDCs on mammalian reproductive development, especially for those EDCs that act via different mechanisms. So as a result of growing concerns about mixture exposure in reality recently, research on EDC mixture exposure during pregnancy and lactation have became a focus in andrology and toxicology (Kortenkamp, 2008). Studies evaluating the effect of DEHP in combination with genistein have been lacking. In this study, we mainly investigated the changes produced by the co-administration of DEHP and genistein during pregnancy and lactation on male offspring testis histology, serum testosterone, anogenital distance and mRNA expression on postnatal day1 and postnatal day 22 .

\section{METHODS}

Animals

Prior to initiation of the study, the experimental protocol was reviewed and approved by the Committee on Animal Research and Ethics of Xi'an Jiaotong University (Xi'an, P.R.China). Specific pathogen-free (SPF) Sprague-Dawley rats were obtained from the Experimental Animal Center of $\mathrm{Xi}^{\prime}$ an Jiaotong University and kept under 12-h light/ dark cycle within the temperature range of $21 \pm 2{ }^{\circ} \mathrm{C}$, relative humidity held constant at $50 \pm 5 \%$. Soy- and alfalfa-free diet (SAFD) and purified water were provided ad libitum.

\section{Chemicals and F0 treatment}

Di-2-(ethylhexyl) phthalate (DEHP) CAS: 117-81-7 was obtained from Tianjin Kermel Chemical Reagent Co., Ltd (Tianjin, P.R.China); Genistein CAS: 446-72-0, was obtained from Shaanxi Huike Botanical Development Co., Ltd (Xi'an, P.R.China); peanut oil was obtained from Longda Co., Ltd (Yantai, P.R.China).

Forty-eight eight-week-old virgin SD female rats (F0 generation) were housed two per cage on arrival. Each pair of female rats was mated overnight with one male adult rat. Vaginal smears were collected early in the morning daily and the day of sperm detection was considered as gestation day 0 (GD0). Once insemination was confirmed, the first thirty-six sperm positive female rats were weighed, housed individually and randomly allocated to five treatment groups. F0 pregnant rats were treated by daily gavage from gestation day 3 (GD3) to postnatal day 21(PND21) with peanut oil (vehicle control), DEHP $250 \mathrm{mg} / \mathrm{kg}$ body weight (bw)/day (DEHP 250), GEN $50 \mathrm{mg} / \mathrm{kg}$ bw/day (GEN 50), GEN $400 \mathrm{mg} / \mathrm{kg}$ bw/day (GEN 400), a combination of DEHP $250 \mathrm{mg} / \mathrm{kg}$ bw/day and GEN $50 \mathrm{mg} / \mathrm{kg} \mathrm{bw} /$ day (DEHP 250+GEN 50), or a combination of DEHP $250 \mathrm{mg} / \mathrm{kg}$ bw/day and GEN $400 \mathrm{mg} / \mathrm{kg}$ bw/ day (DEHP 250+GEN 400). DEHP and GEN were dissolved in peanut oil and peanut oil was administrated at a dose of $2 \mathrm{ml} / \mathrm{kg}$. There was a 1-day interruption of treatment on the day of parturition (PND0).The dose of each chemical was calculated daily according to body weight for each dam before dosing. Offspring were weaned on PND21 when F0 rats were euthanized.

The doses of DEHP and genistein were chosen on the basis of previous reports (Shirota et al., 2005; Michael et al., 2006); we expected that the selected doses of DEHP $250 \mathrm{mg} / \mathrm{kg}$ / day would produce small but not significant changes, if any, on endpoints such as testicular testosterone level decrease or anogenital distance decrease, therefore any potentially cumulative effects would be better manifested. Serum concentration of phytoestrogen under a classical Asian diet is equivalent to that of a rat at the dose of $40-50 \mathrm{mg} / \mathrm{kg}(\mathrm{H}$ et al., 1993; KS et al., 2001) and the no observed adverse effect level (NOAEL) of genistein is considered to be $50 \mathrm{mg} / \mathrm{kg} /$ day (Michael et al., 2006). No treatment-related teratogenic effects were noted in body weight, normalized anogenital distance, serum testosterone or sperm concentration in the male offspring after exposure to GEN $300 \mathrm{mg} / \mathrm{kg}$ bw/ day (Wisniewski et al., 2005) and GEN $500 \mathrm{mg} / \mathrm{kg} \mathrm{bw} /$ day (McClain et al., 2007) during pregnancy.

\section{F1 treatment}

Body weights of pups were determined on PND 1 and PND 22. Anogenital distances were measured using a Vernier caliper by a single investigator in a blind manner on PND 1 and PND22. The AGD of each animal was divided by the cube root of body weight to avoid errors caused by differences in body size. On PND 21, pups were moved from their mothers and housed by litter and sex. One litter of the (DEHP 250+GEN 400) group died because there was no milk secreted by the dam, so that only five dams remained in this group. On PND22, two to three F1 male offspring per litter were anaesthetized using $10 \%$ chloral hydrate. Blood samples were taken from the inferior vena cava and centrifuged at $3500 \mathrm{rpm}$ for $10 \mathrm{~min}$. Serum was exacted and stored at $-80{ }^{\circ} \mathrm{C}$. Serum testosterone was tested with a testosterone radioimmunoassay kit (Tianjin Nine Tripods Medical \&Bioengineering Co., Ltd, P.R.China) according to manufacturer's instructions. The right testis of each pup was removed and stored in liquid nitrogen and then transferred to a $-80{ }^{\circ} \mathrm{C}$ freezer for later analysis of gene expression. The left testis, liver, left kidney and spleen of these pups were removed and weighted and the testis was immediately placed in Bouin's fixative solution for $12 \mathrm{~h}$ and routinely processed for histology.

\section{Testicular Histology}

After fixation in Bouin's fixative solution, testes collected on PND22 were transferred to $75 \%$ ethanol, embedded in paraffin and cut at $5 \mu \mathrm{m}$. Sections were stained with haematoxylin and eosin and evaluated by light microscopy. The diameter of at least twenty randomly selected round cords per testis was measured via Image-Pro-Plus 5.0 version (Media Cybernetics, USA) and the ratio of seminiferous cords/seminiferous tubules was calculated at the same time. Those evaluations were performed by an experienced investigator blind to the treatment group.

\section{Testicular RNA isolation and RT-PCR}

Right testes of male offspring were taken from the $-80{ }^{\circ} \mathrm{C}$ freezer and immediately ground on ice homogeneously in a plate containing $2 \mathrm{ml}$ DEPC-treated PBS. For total RNA isolation, the suspension later was transferred to RNAasefree Eppendorf tubes. Total RNA was isolated according to instructions of the Fast 200 RNA isolation kit (Fastgen biotechnology Co, Shanghai, P.R .China). Total RNA was 
quantified (A260) and assessed for purity (A260/A280) by spectrophotometry. Then reverse transcription was carried out using a RevertAid First Strand cDNA Synthesis Kit (Fermentas, Lithuania) according to manufacturer's instructions.

Reverse transcription polymerase chain reaction (RT-PCR) was performed on a PTC-200 DNA Engine from MJ Research (now Bio-Rad). The genes, primer sequences and optimal amplification conditions are listed in Table 1. Amplification of cDNA was performed using the PCR mix (Applied Biosystems) according to the manufacturer's instructions. The relative level of mRNA was standardized to the housekeeping genes $\beta$-actin in order to control for differences in RNA loading, quality and cDNA synthesis. RT-PCR was performed in a reaction volume of $25 \mu \mathrm{l}$ containing $12.5 \mu \mathrm{l} 2 \times \mathrm{PCR}$ Mix, $1 \mu \mathrm{l}$ forward primer, $1 \mu \mathrm{l}$

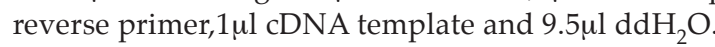

\section{Statistical analysis}

Data were expressed (mean \pm SD) and analyzed using SPSS 13.0 (SPSS Inc., Chicago, IL, USA). Normality and homogeneity of variances were evaluated prior to statistical analysis. Data were analyzed by one-way analysis of variance (ANOVA) followed by the Games-Howell post-hoc test when the results of the ANOVA were significant. In all analyses, litters were used as the statistical units. Differences were considered to be statistically significant at a probability level of $5 \%(P<0.05)$.

\section{RESULTS}

Maternal data and Offspring data on PND1

As expected, no signs of general toxicity were observed in any experimental group. Briefly, there was no significant effect on maternal weight gain, litter size, sex ratio, number of viable pups or AGD/(bodyweight $)^{1 / 3}$ at any dose tested. But body weight of male offspring significantly decreased in group DEHP250 +GEN50 (compared to the control) and group DEHP250 +GEN400 (compared to the other five groups) (Table 2).

Serum testosterone concentration

Exposure to either DEHP $250 \mathrm{mg} / \mathrm{kg}$ bw / day, GEN $400 \mathrm{mg} / \mathrm{kg}$ bw/day or GEN $400 \mathrm{mg} / \mathrm{kg}$ bw/ day resulted in slight but nonsignificant reductions in serum testosterone levels compared to the control (Fig. 1). In contrast, co-administration of the two chemicals resulted in a significant reduction of testosterone when exposed to DEHP250mg/kg bw/d+GEN50mg/kg

TABLE 1

Genes, primer sequences and amplification size for RT- PCR

\begin{tabular}{cccc}
\hline Gene & Primer & Product length $(\mathbf{b p})$ & $\operatorname{Tm}\left({ }^{\circ} \mathbf{C}\right)$ \\
\hline B-actin & P1 5-ACTATCGGCAATGAGCGGTTCC-3 & $148 \mathrm{bp}$ & 60 \\
& P2 5-CTGTGTTGGCATAGAGGTCTTTACG-3 & & \\
Cyp17a1 & P1 5-CTATCCGAGAAGTGCTGCGTATC-3 & 224bp & 61 \\
& P2 5-CTGCGTGGGTGTAATGAGATGG-3 & & \\
Star & P1 5-TTCTCAACTGGAAGCAACACTCTAC-3 & $166 \mathrm{bp}$ & 63 \\
& P2 5-ACCTGGCACCACCTTACTTAGC-3 & & \\
Scarb1 & P1 5-GCAGTGATGATGGAGGACAAGC-3 & 232bp & 63 \\
& P2 5-AGACGGTGAAGACGCCAGAAC-3 & & \\
Cyp11a1 & P1 5-GGGCTTTGGCTGGGGTGTTC-3 & $181 \mathrm{bp}$ & 62 \\
& P2 5-AGGCTGGAAGTTGAAGAAGATAGGC-3 & & \\
\hline
\end{tabular}

TABLE 2

Maternal data and offspring data following oral exposure to DEHP and/or GEN on PND1

\begin{tabular}{ccccccc}
\hline Treatment(mg/kg/day) & litters & $\begin{array}{c}\text { Weight gain } \\
\text { GD3-GD21(g) }\end{array}$ & $\begin{array}{c}\text { No. of viable } \\
\text { pups }\end{array}$ & $\begin{array}{c}\text { Sex ratio } \\
\text { (female:male) }\end{array}$ & $\begin{array}{c}\text { Body weight of } \\
\text { male offspring }\end{array}$ & $\begin{array}{c}\text { AGD/(body } \\
\text { weight) }\end{array}$ \\
\hline Control & 6 & $110.2 \pm 15.4$ & $12.50 \pm 1.64$ & $0.92: 1$ & $6.60 \pm 0.89$ & $2.42 \pm 0.28$ \\
DEHP250 & 6 & $98.5 \pm 10.1$ & $12.33 \pm 1.86$ & $0.85: 1$ & $6.27 \pm 0.81$ & $2.31 \pm 0.19$ \\
GEN50 & 6 & $106.4 \pm 11.5$ & $12.16 \pm 1.53$ & $0.97: 1$ & $6.48 \pm 0.93$ & $2.35 \pm 0.32$ \\
GEN400 & 6 & $114.9 \pm 19.3$ & $11.67 \pm 1.75$ & $1.12: 1$ & $6.23 \pm 0.72$ & $2.39 \pm 0.34$ \\
DEHP250+GEN50 & 6 & $96.1 \pm 6.7$ & $13.33 \pm 1.75$ & $0.91: 1$ & $6.14 \pm 0.37^{*}$ & $2.26 \pm 0.25$ \\
DEHP250+GEN400 & 6 & $101.5 \pm 13.9$ & $13.0 \pm 1.79$ & $1.05: 1$ & $5.24 \pm 0.81^{* * \# \div}$ & $2.25 \pm 0.22$ \\
\hline
\end{tabular}

Values are litter mean \pm standard deviation. Games-Howell post-hoc test: $*$ : Significantly different from control group at $P<0.05, * *$ : Significantly different from control group at $P<0.01$, \#: Significantly different from DEHP250 at $P<0.05 ; \div$ : Significantly different from GEN50 at $P<0.05 ; \diamond:$ Significantly different from GEN400 at $P<0.05$; : : Significantly different from DEHP250+GEN50 at $P<0.05$. 
$\mathrm{bw} / \mathrm{d}$ (compared to the control, GEN50 and GEN400) and DEHP250mg $/ \mathrm{kg}$ bw $/ \mathrm{d}+\mathrm{GEN} 400 \mathrm{mg} / \mathrm{kg} \mathrm{bw} / \mathrm{d}$ (compared to the control, DEHP250, GEN50 and GEN400) .

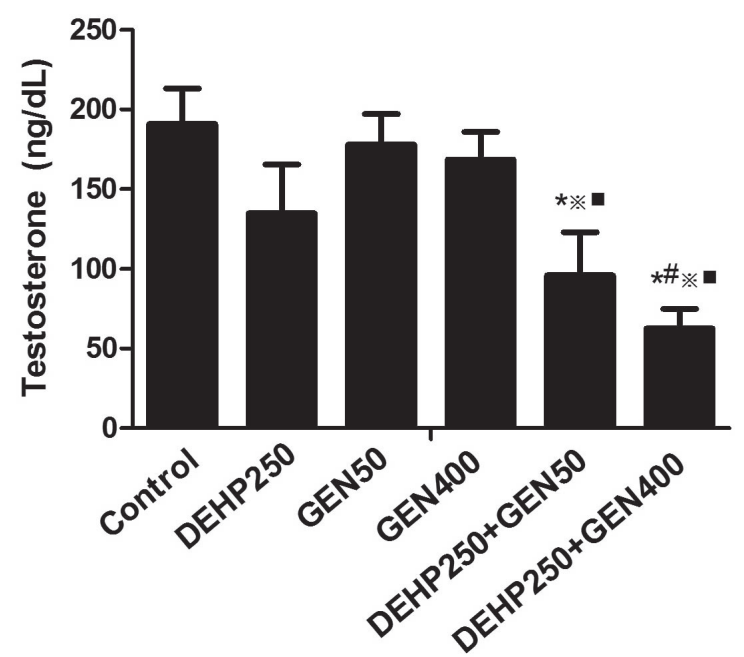

Figure 1. Serum testosterone levels collected on PND 22 from control DEHP and/or GEN-exposed rats. Values are litter mean \pm standard deviation. Note the considerable decrease in group DEHP 250 +GEN50, DEHP 250 +GEN400. There were 14, 14, 13, 15, 13 and 10 male offspring rats in each group, respectively. Statistical differences between control and treated groups were determined using an ANOVA followed by Games-Howell post-hoc test when results of the ANOVA were significant. *:Significantly different from control group at $P<0.05$, \#:Significantly different from DEHP250 at $P<0.05, ※$ : Significantly different from GEN50 at $P<0.05$, n.: Significantly different from GEN400 at $P<0.05$

\section{Offspring data on PND22}

Body weight, organ weight and organ coefficient and AGD/ body weight ${ }^{1 / 3}$ of male rat offspring on postnatal day 22 are shown in Table 3 . The organ coefficient was calculated as (weight of organ)/(body weight). When exposed to DEHP $250 \mathrm{mg} / \mathrm{kg}$ bw/day + GEN $50 \mathrm{mg} / \mathrm{kg}$ bw/day, a significant decrease was observed in both epididymis weight and epididymis coefficient compared to the control, GEN 50 and GEN 400; no significant differences were observed in AGD/ body weight $^{1 / 3}$ in this group. Exposure to DEHP $250 \mathrm{mg} / \mathrm{kg}$ $\mathrm{bw} /$ day + GEN $400 \mathrm{mg} / \mathrm{kg}$ bw/ day caused significant decrease in body weight and testicular weight and testicular coefficient (compared to the control and GEN 50), epididymis weight and epididymis coefficient (compared to the control, DEHP250 and GEN 50) and kidney coefficient (compared to the control). Significant differences in AGD/body weight ${ }^{1 / 3}$ were observed in DEHP250+GEN400 compared to the control, DEHP250 and GEN 50. Malformations of the external genitalia or cryptorchidism were not observed at any dose tested (Table 3).

\section{Testicular histology}

Testicular sections of male offspring rats, seminiferous cord diameter of the testis and ratio of seminiferous cord/ seminiferous tubules on postnatal day 22 are shown in Figure 2 and Figure 3 separately. Diameter and germ cell development of groups DEHP250 and DEHP250 +GEN50 were not significantly different from the control, but cell layers of the two groups were thinner than control layers. The diameter of the seminiferous cords of group DEHP250 +GEN400 was significantly reduced with relatively few cell layers compared to the control and GEN 400 , indicating delayed development of the testis. The ratios of

TABLE 3

Organ weight, organ coefficient and AGD/body weight ${ }^{1 / 3}$ on PND22 in DEHP and/or GEN-exposed male offspring rats

\begin{tabular}{|c|c|c|c|c|c|c|}
\hline & Control & DEHP250 & GEN50 & GEN400 & DEHP250+GEN50 & DEHP250+GEN400 \\
\hline litters & 6 & 6 & 6 & 6 & 6 & 5 \\
\hline No.of male offspring & 14 & 14 & 13 & 15 & 13 & 10 \\
\hline Body weight(g) & $54.6 \pm 4.3$ & $50.3 \pm 3.9$ & $52.8 \pm 4.1$ & $50.2 \pm 5.1$ & $49.3 \pm 4.7$ & $43.3 \pm 6.4^{*} \div$ \\
\hline \multirow[t]{2}{*}{ Testis (mg) (\%) } & $142.5 \pm 15.9$ & $127.6 \pm 16.6$ & $135.2 \pm 17.3$ & $124.5 \pm 18.4$ & $121.7 \pm 15.3$ & $103.7 \pm 16.9^{*} \div$ \\
\hline & $0.263 \pm 0.021$ & $0.252 \pm 0.026$ & $0.258 \pm 0.022$ & $0.250 \pm 0.031$ & $0.249 \pm 0.010$ & $0.230 \pm 0.008^{*} \div$ \\
\hline \multirow[t]{2}{*}{ Epididymis (mg) (\%) } & $43.6 \pm 7.4$ & $41.3 \pm 8.2$ & $40.8 \pm 9.1$ & $38.6 \pm 6.4$ & $31.9 \pm 4.5^{\text {*\# } \div}$ & $29.4 \pm 7.2^{\text {*\# } \div}$ \\
\hline & $0.0821 \pm 0.033$ & $0.0819 \pm 0.029$ & $0.0807 \pm 0.031$ & $0.0726 \pm 0.026$ & $0.0492 \pm 0.009^{* \#} \div$ & $0.0465 \pm 0.005^{\text {*\# }} \div$ \\
\hline \multirow[t]{2}{*}{ Kidney $(\mathrm{mg})(\%)$} & $345.2 \pm 38.9$ & $301.4 \pm 20.6$ & $317.1 \pm 38.5$ & $323.8 \pm 29.4$ & $296.3 \pm 27.4$ & $291.5 \pm 41.6$ \\
\hline & $0.642 \pm 0.107$ & $0.585 \pm 0.027^{*}$ & $0.608 \pm 0.073$ & $0.624 \pm 0.029$ & $0.611 \pm 0.056$ & $0.542 \pm 0.035^{\star}$ \\
\hline \multirow[t]{2}{*}{ Spleen $(\mathrm{mg})(\%)$} & $141.6 \pm 12.8$ & $127.3 \pm 13.2$ & $130.5 \pm 12.9$ & $122.6 \pm 14.7$ & $119.4 \pm 13.5$ & $120.8 \pm 10.4$ \\
\hline & $0.268 \pm 0.037$ & $0.242 \pm 0.025$ & $0.251 \pm 0.046$ & $0.240 \pm 0.038$ & $0.256 \pm 0.032$ & $0.247 \pm 0.019$ \\
\hline \multirow[t]{2}{*}{ Liver $(m g)(\%)$} & $2249.7 \pm 196.2$ & $1789.3 \pm 252.1$ & $2046.4 \pm 148.9$ & $1837.2 \pm 127.4$ & $1793.1 \pm 246.5$ & $1715.7 \pm 165.4$ \\
\hline & $4.13 \pm 0.506$ & $3.56 \pm 0.229$ & $4.07 \pm 0.452$ & $3.93 \pm 0.243$ & $3.84 \pm 0.391$ & $3.58 \pm 0.331$ \\
\hline AGD/body weight ${ }^{1 / 3}$ & $5.08 \pm 0.23$ & $4.83 \pm 0.30$ & $4.92 \pm 0.47$ & $4.67 \pm 0.39$ & $4.54 \pm 0.53$ & $4.26 \pm 0.58^{\star * \# \div}$ \\
\hline
\end{tabular}

Values are litter mean \pm standard deviation. Organ weights are presented as absolute and relative (\%) weights (organ coefficient). Games-Howell post-hoc test: *: Significantly different from control group at $P<0.05$, **: Significantly different from control group at $P<0.01$, \#: Significantly different from DEHP250 at $P<0.05 ; \div$ : Significantly different from GEN50 at $P<0.05$. 

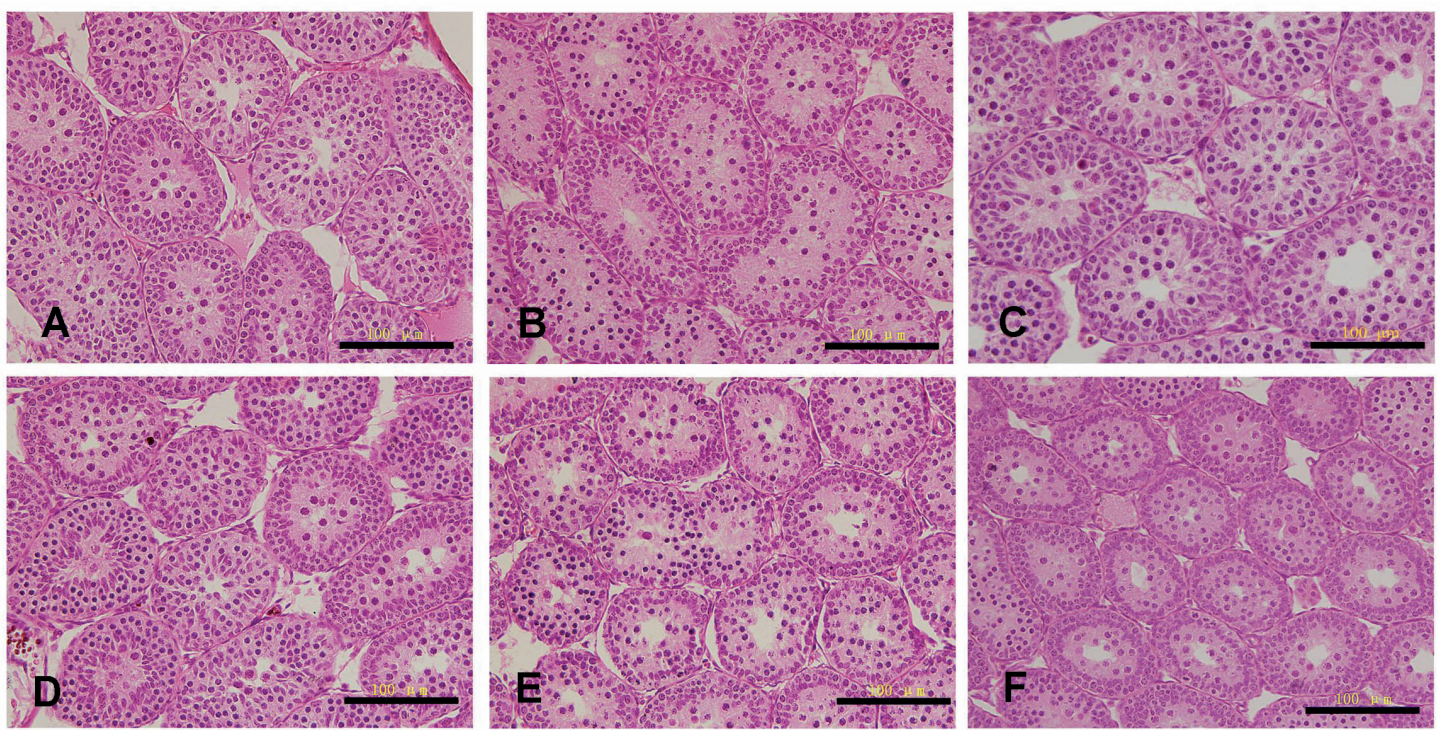

Figure 2. Testicular sections of male offspring on PND 22 after gestational and lactational exposure to vehicle (A), DEHP $250 \mathrm{mg} / \mathrm{kg}$ bw/ day (B), GEN $50 \mathrm{mg} / \mathrm{kg}$ bw/day(C), GEN400 mg/kg bw/day(D),DEHP $250 \mathrm{mg} / \mathrm{kg}$ bw/day+GEN50 mg/kg bw/day(E) and DEHP $250 \mathrm{mg} /$ $\mathrm{kg}$ bw/day+GEN400 mg/kg bw/day (F). There were 14, 14, 13, 15, 13 and 10 male offspring rats in each group, respectively. Note the significant decrease of diameter of the seminiferous cords as well as reduced cell layers in group DEHP250 +GEN400 .400×magnification. Scale bars indicate $100 \mu \mathrm{m}$.
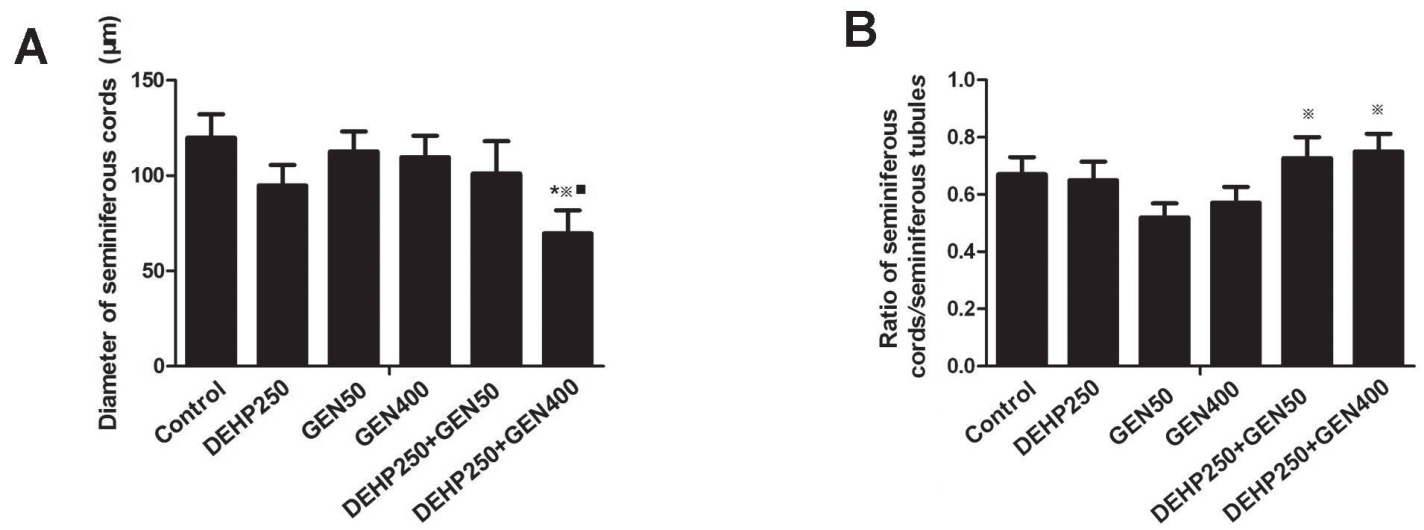

Figure 3. Seminiferous cord diameter of the testes (A) and ratio of seminiferous cords/seminiferous tubules (B) of male offspring on PND 22 after gestational and lactational exposure to vehicle, DEHP $250 \mathrm{mg} / \mathrm{kg}$ bw/day, GEN $50 \mathrm{mg} / \mathrm{kg}$ bw/day, GEN $400 \mathrm{mg} / \mathrm{kg}$ bw/day, DEHP $250 \mathrm{mg} / \mathrm{kg}$ bw/day+GEN50 mg/kg bw/day and DEHP $250 \mathrm{mg} / \mathrm{kg}$ bw/day+GEN400 mg/kg bw/day. A) Note the considerable decrease in group DEHP $250+$ GEN400. B) Note the significantly lower ratio of seminiferous cords/seminiferous tubules in group DEHP $250+$ GEN50 and group DEHP $250+$ GEN400 compared with group GEN50. There were 14, 14, 13, 15, 13 and10 male offspring rats in each group, respectively. Results were expressed as litter mean \pm standard deviation. Statistical differences between control and treated groups were determined using an ANOVA followed by Games-Howell post-hoc test when results of the ANOVA were significant. *:Significantly different from control group at $P<0.05$, ※: Significantly different from GEN50 at $P<0.05$, п: Significantly different from GEN400 at $P<0.05$.

seminiferous cords/seminiferous tubules in group DEHP 250 +GEN50 and group DEHP 250 +GEN400 were significantly lower compared to group GEN50. No significant effects were observed in the diameter and germ cell development of seminiferous cords of animals in group GEN 400 .

\section{Testicular gene expression}

Exposure to DEHP250 mg/ $\mathrm{kg}$ bw/day or GEN400 mg/ $\mathrm{kg}$ bw/day did not significantly affect genes involved in the steroidogenic pathway Star, Cyp17a1, Scarb1 or Cyp11a1 mRNA levels on PND22. Expression of the Star of group DEHP 250 +GEN400 was less than in the control, group GEN50 and group GEN400; expression of Cypal17a1 of the two mixture exposed groups was lower than that of the control group (both groups) and group GEN50 (group DEHP $250+$ GEN50) $(P<0.05)$; Scarb1 of group DEHP $250+$ GEN50 expressed less than the control and group GEN50 $(P<0.05)$; there was no significant difference in Cyp11a1 between groups $(P>0.05)$, which was not altered after exposure in any group (Figure 4 ). 

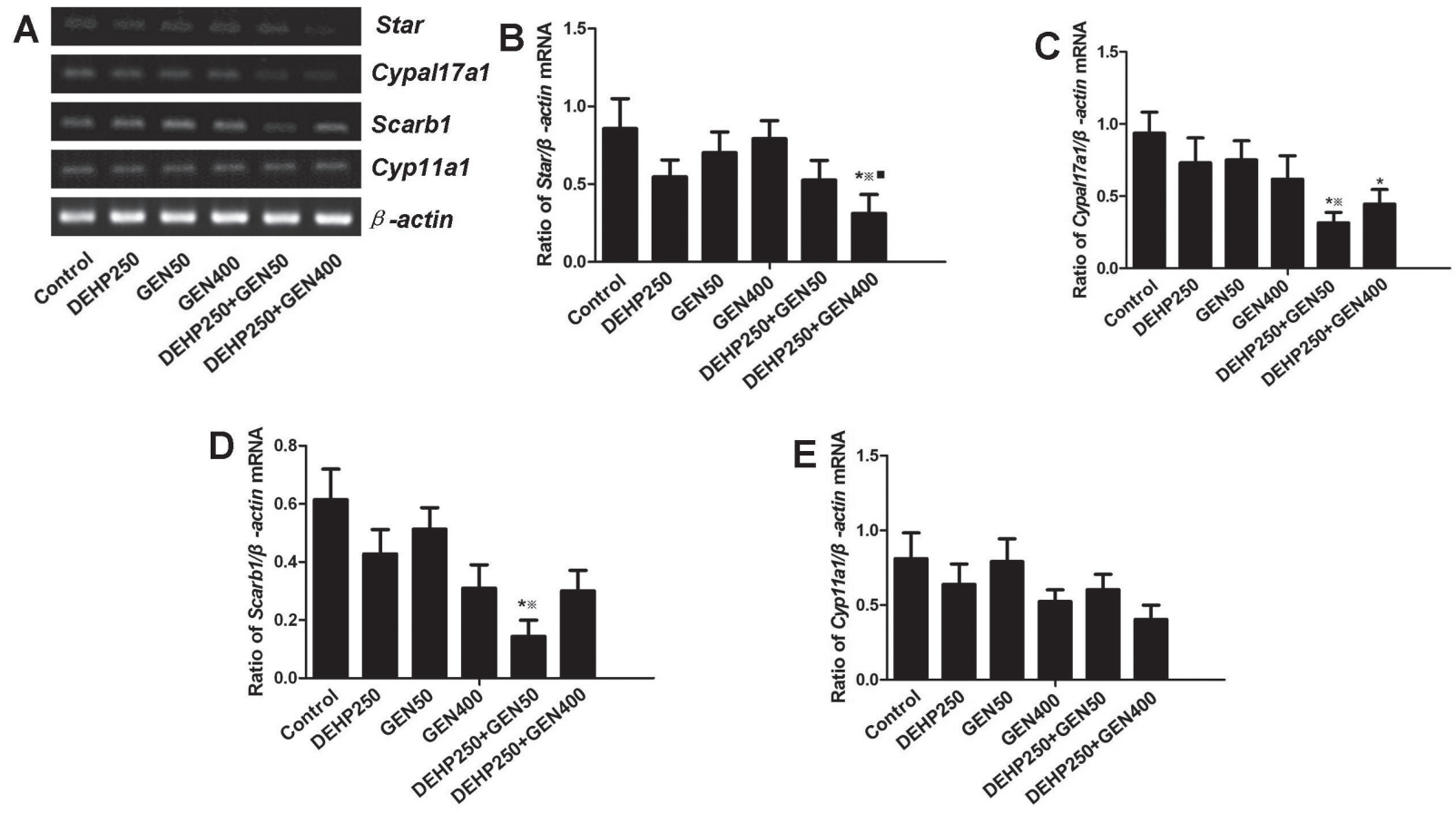

Figure 4. Testicular gene expression of control, DEHP and/or GEN-exposed male offspring on PND 22 after gestational and lactational exposure. (A) gene expression determined by RT-PCR.(B) the expression of Star in group DEHP 250 +GEN400 was significantly lower than the control, group GEN50 and group GEN400(P<0.05).(C) the expression of Cyp17a1 in group DEHP $250+$ GEN50, DEHP 250 +GEN400 showed significant decrease compared to the control (group DEHP $250+$ GEN50, DEHP $250+$ GEN400)and group GEN50 (group DEHP $250+$ GEN50) $(P<0.05)$. (D) the expression of Scarb 1 in group DEHP $250+$ GEN50 was decreased significantly compared to the control and group GEN50 $(P<0.05)$.(E) the expression of Cypllal showed no significant difference between the groups $(P>0.05)$. There were 14, $14,13,15,13$ and 10 male offspring rats in each group, respectively. Results were expressed as litter mean \pm standard deviation. Statistical differences between control and treated groups were determined using an ANOVA followed by Games-Howell post-hoc test when results of the ANOVA were significant.*:Significantly different from control group at $P<0.05$, ※: Significantly different from GEN50 at $P<0.05$, n: Significantly different from GEN400 at $P<0.05$

\section{DISCUSSION}

The endocrine disruptor hypothesis states that early developmental exposure to environmental disrupting chemicals can disrupt male reproductive development and impair fertility (Casals-Casas \& Desvergne, 2011; Skakkebaek et al., 2001; Yiee and Baskin, 2010). In the present study we evaluated the effects of gestational and lactational exposure to DEHP and/ or genistein on the sexual development of male offspring rats. Exposure to DEHP250 mg/ $\mathrm{kg}$ bw/day, GEN50 mg/ $\mathrm{kg}$ bw/day or GEN400 $\mathrm{mg} / \mathrm{kg}$ bw/day alone did not have a significant detrimental effect on male offspring development, including body weight, serum testosterone, corrected AGD organ coefficient and histology of testis, although exposure to single chemicals may cause a slight but not significant effect. We also did not find any significant alteration of the transcripts of key proteins of the steroidogenic pathway such as Star, Cyp17a1, Scarb1 and Cyp11a1 and we may suppose that these alterations were too small to be detected. Vo et al. (2009) demonstrated that in utero administration of DEHP at $100 \mathrm{mg} /$ $\mathrm{kg} /$ day and $500 \mathrm{mg} / \mathrm{kg} /$ day to SD rats from GD11 to GD21 was able to reduce the sperm concentration, viability and motility of the male offspring, but no significant reduction of testis weight, epididymis weight, prostate weight or testosterone level of the male offspring were observed at PND63, or for gene expression such as Star, Cyp11a1, Hsd3b1, etc. on GD21. Mariko Shirota et al. (2005) found that after exposure to DEHP at doses of 125, 250 and $500 \mathrm{mg} / \mathrm{kg} /$ day during GD7-GD18 there was no abnormality in the testes at 5 and 10 weeks after birth in any of the treated groups, which is in agreement with our study. Although variability might exist in the response of rats to DEHP across different laboratories, individual doses of DEHP that are similar to the dose selected in our study have been demonstrated to produce responses that are at borderline significance for several endpoints such as testosterone production, anogenital distance and nipple retention. But those studies mostly focused on exposure during either gestation or lactation and did not cover both the gestation and lactation periods, which are two critical periods for masculinization. Recently Pocar et al (2012) reported more severe reproductive toxicity of male offspring mice on PND 42 after maternal exposure to DEHP at relatively low doses from GD 0.5 to the end of lactation. The differences with our study may largely due to different end points of observation and different species; DEHP administration cannot produce immediate reproductive toxicity because of its delayed effect on HPG and Leydig cell maturation, so it is necessary to observe the long-term reproductive outcome. However, DEHP administration via chow intake cannot assure accurate DEHP dosage because body weight and chow intake do not have linear correlation. 
Dietary exposure to isoflavones plays an important role in various physiological processes in the body. It is well known that genistein, an isoflavone found in soybeans and soy products, has both estrogenic (Cederroth et al., 2010) and antioxidant effects (Qian et al., 2012). In our study, the effect of genistein on the male offspring also appears to be negligible. This is in accordance with previous reports of no major alterations in the reproductive system of SD rats exposed during gestation and/or lactation to high or low phytoestrogen diets. Wisniewski et al. (2005) showed that after receiving a phytoestrogen-free diet supplemented with 0,5 or $300 \mathrm{mg} / \mathrm{kg}$ of genistein throughout gestation and lactation, timing of preputial separation, adult reproductive behavior, sperm concentrations and testosterone production were not influenced by genistein treatment at either dose. But previous studies did not examine the toxicity of genistein exposure in utero and lactation at $400 \mathrm{mg} / \mathrm{kg}$ bw/day. In an in vitro study (Lehraiki et al., 2011) in organ cultures of fetal testes from wild type and ER alpha or ER beta knockout mice showed that genistein inhibits testosterone secretion by fetal Leydig cells during early fetal development, while in this in vivo study we did not observe any modification of serum testosterone production in the neonate.

Co-administration of DEHP and GEN (at $50 \mathrm{mg} / \mathrm{kg} \mathrm{bw} /$ day or $400 \mathrm{mg} / \mathrm{kg} \mathrm{bw} /$ day) from gestation day 3 to postnatal day 22 significantly reduced the body weight of male offspring, serum testosterone levels, epididymis coefficient, testis coefficient (Group DEHP+GEN400) and AGD / (body weight) ${ }^{1 / 3}$ (Group DEHP+GEN400) in male offspring on PND22 at doses that individually had no significant effect on this variable. The DEHP and genistein (at low and high doses) mixture produced more significant alterations than DEHP or genistein alone, especially when DEHP was co-administrated with genistein at $400 \mathrm{mg} / \mathrm{kg}$ bw/day. This evokes a cumulative effect after exposure to the mixture. Genistein has been reported to exhibit in vitro anti-androgenic activity in addition to its well-established estrogenic activity especially at high dose (Rosenberg et al., 2000). This type of mechanism may act in vivo and contribute to some of the anti-androgenic demasculinizing effects observed here. Eustache et al. (2009) observed a deleterious synergistic effect of low doses of genistein and vinclozolin on fertility using a similar experimental procedure. The steroidogenic acute regulatory protein Star, a protein involved in the transfer of cholesterol from the cytosol to the outer mitochondrial membrane, plays a key role in the acute regulation of steroid hormone synthesis by enhancing the conversion of cholesterol into pregnenolone. The combination of DEHP and high-dose GEN, down-regulated the expression of Star, as well as 17- $\alpha$ hydroxylase (Cypal17a1). Scavenger receptor class B (Scarb1) Cypal17a1 was also down-regulated with DEHP co-administrated with GEN at low dose. The modification of genes involved in the steroidogenic pathway was probably responsible for the following events, which regulated testosterone production, epididymis and testis development. AGD or corrected AGD, which is a non-invasive index of masculinization, hypospadias and cryptorchidism, may be associated with reduced anogenital distance as a result of endocrine disruption (MH et al., 2008) . AGD/(body weight $)^{1 / 3}$ in Group DEHP+GEN400 were significantly reduced compared to the control and DEHP exposure alone, which means deterioration of the masculinization process and may further impair the fertility of male offspring.
Several studies have been recently published on possible cumulative effects of endocrine disruptors in rats. However, their focus has been mostly on exposure to endocrine disruptors of the same category or which act as anti-androgens, such as phthalates (Hass et al., 2007; Rider et al., 2008; Rider et al., 2009; Rider et al., 2010). Research on different species of endocrine disruptors has been seldom published. Our research demonstrated firstly that a natural phytoestrogen, genistein, can exacerbate the deleterious effect of the most commonly used plasticizer DEHP when exposed during gestation and lactation, especially when genistein was co-administrated at a high dose. It is also necessary to observe the reproductive effect on the adult male offspring, especially when exposed to the mixture. Previously Yousef et al (2003) demonstrated the beneficial influence of isoflavones in reducing the negative effects of cypermethrin on thr reproductive characteristics of mature male New Zealand white rabbits when given every other day for 12 weeks. While previous studies mainly focused on genistein exposure at relatively lower dose, especially when co-administrated (Eustache et al., 2009; Lehraiki et al., 2011; You et al., 2002), in our study for the first time genistein was co-administrated at high dose with DEHP. This emphasizes the importance of further observation and continuous study of reproductive toxicology evaluation of co-administration.

\section{ACKNOWLEDGEMENTS}

We thank Dr De-Lai Fu (Department of Urology, the Second Affiliated Hospital, School of Medicine, Xi'an Jiaotong University) for assistance and various suggestions with respect to the animal model. We thank Professor Tao Shi, Dr Peng Zhang (Department of Urology, the Second Affiliated Hospital, School of Medicine, Xi'an Jiaotong University) for critical evaluation of the manuscript and helpful experimental suggestions. We also thank Dr Yong-Wei Huo (Department of Anatomy and Histoembryology, Medicine School of Xi'an Jiaotong University) for her kind technical support and helpful discussions with respect to H\&E staining.

\section{REFERENCES}

CASALS-CASAS C, DESVERGNE B (2011) Endocrine Disruptors: From Endocrine to Metabolic Disruption. Annu Rev Physiol 73: 135-162.

CEDERROTH CR, AUGER J, ZIMMERMANN C, EUSTACHE F, NEF S (2010) Soy, phyto-oestrogens and male reproductive function: a review. Int J Androl 33: 304-316.

CHRISTIANSEN S, BOBERG J, AXELSTAD M, DALGAARD M, VINGGAARD AM, METZDORFF SB, HASS U (2010) Low-dose perinatal exposure to di(2-ethylhexyl) phthalate induces anti-androgenic effects in male rats. Reprod Toxicol 30: 313-321.

CULTY M, THUILLIER R LIW, WANG Y, MARTINEZ-ARGUELLES DB, BENJAMIN CG, TRIANTAFILOU KM, ZIRKIN BR, PAPADOPOULOS V (2008) In utero exposure to di-(2-ethylhexyl) phthalate exerts both shortterm and long-lasting suppressive effects on testosterone production in the rat. Biol Reprod 78:1018-1028.

DUNCAN AM, PHIPPS WR, KURZER MS (2003) Phyto-oestrogens. Best Pract Res Clin Endocrinol Metab 17: 253-271.

EUSTACHE F, MONDON F, CANIVENC-LAVIER MC, LESAFFRE C, FULLA Y, BERGES R, CRAVEDI JP, VAIMAN D, AUGER J (2009) Chronic dietary exposure to a low-dose mixture of genistein and vinclozolin modifies the reproductive axis, testis transcriptome, and fertility. Environ Health Perspect 117: 1272-1279.

FISHER JS (2004) Environmental anti-androgens and male reproductive health: focus on phthalates and testicular dysgenesis syndrome. Reproduction 127:305-315. 
FOSTER PM (2006) Disruption of reproductive development in male rat offspring following in utero exposure to phthalate esters. Int J Androl 29: 140-147, 181-185.

H A, H M, S W (1993) Plasma concentrations of phyto-oestrogens in Japanese men. Lancet 342:1209-1210.

HASS U, SCHOLZE M, CHRISTIANSEN S, DALGAARD M, VINGGAARD AM, AXELSTAD M, METZDORFF SB, KORTENKAMP A (2007) Combined exposure to anti-androgens exacerbates disruption of sexual differentiation in the rat. Environ Health Perspect 115 Suppl 1: 122-128.

HU GX, LIAN QQ, GE RS, HARDY DO, LI XK (2009) Phthalate-induced testicular dysgenesis syndrome: Leydig cell influence. Trends Endocrinol Metab 20:139-145.

KAMRIN MA(2009) Phthalate risks, phthalate regulation, and public health: a review. J Toxicol Environ Health B Crit Rev 12: 157-174.

KORTENKAMP A (2008) Low dose mixture effects of endocrine disrupters: implications for risk assessment and epidemiology. Int J Androl 31: 233240.

KS W, KD S, DM S, ED L (2001) Dietary soy-phytoestrogens decrease testosterone levels and prostate weight without altering $\mathrm{LH}$, prostate 5alpha-reductase or testicular steroidogenic acute regulatory peptide levels in adult male Sprague-Dawley rats. J Endocrinol 170:591-599.

KUMI-DIAKA J, NGUYEN V, BUTLER A (1999) Cytotoxic potential of the phytochemical genistein isoflavone $\left(4^{\prime}, 5^{\prime}, 7\right.$-trihydroxyisoflavone) and certain environmental chemical compounds on testicular cells. Biol Cell 91: 515-523.

LAGOS-CABRE R, MORENO RD (2012) Contribution of environmental pollutants to male infertily: A working model of germ cell apoptosis induced by plasticizers. Biol Res 45: 5-14.

LEHRAIKI A, CHAMAILLARD C, KRUST A, HABERT R, LEVACHER C (2011) Genistein impairs early testosterone production in fetal mouse testis via estrogen receptor alpha. Toxicol In Vitro 25: 1542-1547.

LEHRAIKI A, MESSIAEN S, BERGES R, CANIVENC-LAVIER MC, AUGER J, HABERT R, LEVACHER C (2011) Antagonistic effects of gestational dietary exposure to low-dose vinclozolin and genistein on rat fetal germ cell development. Reprod Toxicol 31:424-430.

MAIN KM, SKAKKEBAEK N.E, VIRTANEN H.E, TOPPARI J (2010) Genital anomalies in boys and the environment. Best Pract Res Clin Endocrinol Metab 24:279-289.

MCCLAIN RM, WOLZ E, DAVIDOVICH A, EDWARDS J, BAUSCH J(2007) Reproductive safety studies with genistein in rats. Food Chem Toxicol 45: 1319-1332

MH H, BN B, ML E, LS B (2008) Associations among hypospadias, cryptorchidism, anogenital distance, and endocrine disruption. Curr Urol Rep 9: 137-142.

MICHAEL MR, WOLZ E, DAVIDOVICH A, PFANNKUCH F, EDWARDS JA, BAUSCH J (2006) Acute, subchronic and chronic safety studies with genistein in rats. Food Chem Toxicol 44: 56-80.

POCAR P, FIANDANESE N, SECCHI C, BERRINI A, FISCHER B, SCHMIDT JS, SCHAEDLICH K, BORROMEO V (2012) Exposure to di(2-ethylhexyl) phthalate (DEHP) in utero and during lactation causes long-term pituitary-gonadal axis disruption in male and female mouse offspring. Endocrinology 153:937-948.

QIAN Y, GUAN T, HUANG M, CAO L, LI Y, CHENG H, JIN H, YU D (2012) Neuroprotection by the soy isoflavone, genistein, via inhibition of mitochondria-dependent apoptosis pathways and reactive oxygen
induced-NF-kappaB activation in a cerebral ischemia mouse model. Neurochem Int60:759-67.

RIDER CV, FURR J, WILSON VS, GRAY LJ (2008) A mixture of seven antiandrogens induces reproductive malformations in rats. Int J Androl 31:249-262.

RIDER CV, FURR JR, WILSON VS, GRAY LJ (2010) Cumulative effects of in utero administration of mixtures of reproductive toxicants that disrupt common target tissues via diverse mechanisms of toxicity. Int J Androl 33: 443-462.

RIDER CV, WILSON VS, HOWDESHELL KL, HOTCHKISS AK, FURR JR, LAMBRIGHT CR, GRAY LJ (2009) Cumulative effects of in utero administration of mixtures of "antiandrogens" on male rat reproductive development. Toxicol Pathol 37: 100-113.

ROBERTS D, VEERAMACHANENI DN, SCHLAFF WD, AWONIYI CA (2000) Effects of chronic dietary exposure to genistein, a phytoestrogen, during various stages of development on reproductive hormones and spermatogenesis in rats. Endocrine 13:281-286.

ROSENBERG ZR, JENKINS DJ, DIAMANDIS EP (2000) Genistein: a potent natural antiandrogen. Clin Chem 46: 887-888.

SHIROTA M, SAITO Y, IMAI K, HORIUCHI S, YOSHIMURA S, SATO M, NAGAO T, ONO H, KATOH M (2005) Influence of di-(2-ethylhexyl) phthalate on fetal testicular development by oral administration to pregnant rats. J Toxicol Sci 30: 175-194.

SKAKKEBAEK NE, RAJPERT-DE ME, MAIN KM (2001) Testicular dysgenesis syndrome: an increasingly common developmental disorder with environmental aspects. Hum Reprod 16: 972-978.

STROM BL, SCHINNAR R, ZIEGLER EE, BARNHART KT, SAMMEL MD, MACONES GA, STALLINGS VA, DRULIS JM, NELSON SE, HANSON SA (2001) Exposure to soy-based formula in infancy and endocrinological and reproductive outcomes in young adulthood. JAMA 286: 807-814.

TM E, BCM, Jr GL (2006) Reproductive dysgenesis in wildlife: a comparative view. nt J Androl 29:109-121.

TOPPARI J, VIRTANEN HE, MAIN KM, SKAKKEBAEK NE (2010) Cryptorchidism and hypospadias as a sign of testicular dysgenesis syndrome (TDS): environmental connection. Birth Defects Res A Clin Mol Teratol 88: 910-919.

VO TT, JUNG E.M, DANG VH, JUNG K, BAEK J, CHOI KC, JEUNG EB (2009) Differential effects of flutamide and di-(2-ethylhexyl) phthalate on male reproductive organs in a rat model. J Reprod Dev 55:400-411.

WISNIEWSKI AB, CERNETICH A, GEARHART JP, KLEIN SL (2005) Perinatal exposure to genistein alters reproductive development and aggressive behavior in male mice. Physiol Behav 84: 327-334.

WISNIEWSKI AB, KLEIN SL, LAKSHMANAN Y, GEARHART JP (2003) Exposure to genistein during gestation and lactation demasculinizes the reproductive system in rats. J Urol 169:1582-1586.

YIEE JH, BASKIN LS (2010) Environmental factors in genitourinary development. J Urol 184: 34-41.

YOU L, CASANOVA M, BARTOLUCCI EJ, FRYCZYNSKI MW, DORMAN DC, EVERITT JI, GAIDO KW, ROSS SM, HECK HH (2002) Combined effects of dietary phytoestrogen and synthetic endocrine-active compound on reproductive development in Sprague-Dawley rats: genistein and methoxychlor. Toxicol Sci 66: 91-104.

YOUSEF MI, EL-DEMERDASH FM, AL-SALHEN KS (2003) Protective role of isoflavones against the toxic effect of cypermethrin on semen quality and testosterone levels of rabbits. J Environ Sci Health B 38: 463-478. 